\title{
Salt Tolerance Mechanism of Sugarcane and Management Practices under Sodic Soil
}

\author{
S Manjula, A Vadivel and M Jayalakshmi* \\ Depertment of Soil Science, \\ Tamil Nadu Agricultural University, Coimbatore - 641 003, Tamil Nadu, India \\ *Central Research Institute for Dryland Agriculture, Hyderabad - 500 059, Andhra Pradesh, India \\ e-mail: jayalakshmimitnala@gmail.com
}

Received: 26 April 2014; Revised accepted: 18 January 2015

\section{A B S T R A C T}

A field experiment on sugarcane was conducted at Anbil Dharma lingam Agricultural College and Research Institute, Tiruchirapalli with the view to identify sodic tolerant variety and suitable amendment for sodic soil. Four sugarcane varieties viz Co Si (Sc) 6, Co C (Sc) 86032, Co C (Sc) 23 and Co G (Sc) 5 and three amendments viz pressmud @ $12.5 \mathrm{t} \mathrm{ha}^{-1}$, gypsum @ $4.8 \mathrm{t} \mathrm{ha}^{-1}$ and bottom slag @ $15 \mathrm{t} \mathrm{ha}^{-1}$ were studied along with the unamended control in the experiment were studied. The results revealed that sugarcane varieties Co G (Sc) 5 and Co C (Sc) 23 gave higher $\mathrm{K}^{+}: \mathrm{Na}^{+}$as compared to the $\mathrm{Co} \mathrm{Si} \mathrm{(Sc)} 6$ and Co C (Sc) 86032 under sodic soil. The sugarcane varieties namely $\mathrm{Co} \mathrm{G} \mathrm{(Sc)} 5$ and $\mathrm{Co} \mathrm{C} \mathrm{(Sc)} 23$ were found to be superior for accumulating more $\mathrm{K}$ than the $\mathrm{Na}^{+}$, hence these might be considered suitable for growing under sodic soil.

Key words: Saccharum officinarum, Sodic soil, Sugarcane varieties, $\mathrm{K}^{+}$: Na

Sugarcane (Saccharum officinarum L.) is a major source of sucrose and therefore ubiquitous in cultivation. Although it is ranked as moderately salt-sensitive (Francoise and Maas 1999), there are differences in salt resistance (Wahid et al. 1997). Primary metabolism of sugarcane has been well studied under normal or sodic conditions; however, there is a lack of information on the biosynthesis and role of secondary metabolites in sugarcane under sodicity, although they accumulate in low levels under normal conditions (Franca et al. 2001). It is assumed that accumulation of secondary metabolites enhances the sugarcane capacity for salt tolerance. Therefore, the aims of this study wasto determine time course changes in the levels of some secondary metabolites and their physiological implications in salt tolerance of sugarcane.

\section{MATERIALS AND METHODS}

The field experiment was conducted at Anbil Dharmalingam Agricultural College and Research Institute, Tiruchirapalli during June 2007 - May 2008 with the view to identify sodic tolerant variety and suitable amendment for sodic soil. Four sugarcane varieties viz Co $\mathrm{Si}(\mathrm{Sc}) 6$, Co C (Sc) 86032, Co C (Sc) 23 and Co G (Sc) 5 were studied. The experimental soil was sandy loam in texture, belonging to Adavathur soil series, taxonomically termed as Vertic Ustropepts. The soil was alkaline in reaction with $\mathrm{pH} 8.76$ and EC of $0.32 \mathrm{dS} \mathrm{m}^{-1}$ and was low in available nitrogen $\left(224 \mathrm{~kg} \mathrm{ha}^{-1}\right)$, medium in available phosphorus and potassium $\left(12.6,210 \mathrm{~kg} \mathrm{ha}^{-1}\right.$ respectively). The organic carbon content of the soil is medium with 0.65 percent. The exchangeable sodium percentage and cation exchange capacity was 38.3 and 19.6 c mol $\mathrm{p}^{(+)} \mathrm{kg}^{-1}$ respectively. The experiment was laid out in Randomized block design with three replications. Destructive plant samples were collected at, 60, 90, 120, 150, and 180 days after planting. Samples were separated into different parts like leaf, sheath, stem and root. Samples were shade dried and oven dried at $60^{\circ} \mathrm{C}$, then ground and stored in labelled containers for chemical analyses. Wet digestion of a known quantity of plant material was carried out with $15 \mathrm{ml}$ of triple acid (nitric acid, sulphuric acid and perchloric acid in the ratio of 9:2:1, respectively) mixture for $\mathrm{K}$, Na estimation. The digested samples were made up to desired volume and used for the estimation of $\mathrm{K}, \mathrm{Na}$ by using flame photometer.

\section{RESULTS AND DISCUSSION}

The mean $\mathrm{K}$ : $\mathrm{Na}$ ratio of different plant parts at different growth stages of sugarcane have shown higher $\mathrm{K}$ : $\mathrm{Na}$ ratios were associated with $\mathrm{V}_{4}$ and $\mathrm{T}_{3}$ in all plant parts and at all stages of sampling. However, the $\mathrm{K}$ : Na ratio was found to be narrowed with the advancement of crop growth in all parts of sugarcane irrespective of varieties and 
amendments. At later stages of crop growth i e 150 DAP and 180 DAP narrow $\mathrm{K}$ : Na ratios were observed in sheath and root than leaf and stem. The genotypic ability of tolerant varieties in accumulating potassium at higher concentration than susceptible one was observed (Abdul-Wahid 2006). K: $\mathrm{Na}$ ratio was found to be narrowed with the advancement of crop growth at all plant parts of sugarcane irrespective of amendments and varieties. At later stages of crop growth i e 150 DAP and 180 DAP narrow K:Na ratio were observed in sheath and root than leaf and stem. It revealed that the sodium was stored in sheath and root at later stages. Wider $\mathrm{K}$ : Na ratio in leaf at early stages could be used as an indicator of varietals tolerance to sodicity. Gypsum application also showed wider K: Na ratios in leaf.

Table 1 Performance of varieties and effect of amendments on $\mathrm{K}^{+}: \mathrm{Na}^{+}$ratio at different stages of sugarcane

\begin{tabular}{lcccccccccccccccccccccc}
\hline & \multicolumn{4}{c}{ Leaf } & \multicolumn{1}{c}{ Stem } & \multicolumn{1}{c}{ Sheath } & \multicolumn{1}{c}{ Root } \\
\cline { 2 - 6 } & 60 & 120 & 150 & 180 & 60 & 90 & 120 & 150 & 180 & 60 & 90 & 120 & 150 & 180 & 60 & 90 & 120 & 150 & 180 \\
\hline $\mathrm{V}_{1}$ & 1.10 & 0.79 & 0.70 & 0.54 & 0.49 & 1.08 & 0.42 & 0.34 & 0.25 & 0.22 & 0.48 & 0.28 & 0.16 & 0.14 & 0.14 & 0.35 & 0.71 & 0.17 & 0.11 & 0.12 \\
$\mathrm{~V}_{2}$ & 1.24 & 0.84 & 0.51 & 0.48 & 0.39 & 1.12 & 0.48 & 0.39 & 0.29 & 0.24 & 0.52 & 0.31 & 0.17 & 0.15 & 0.15 & 0.65 & 0.24 & 0.16 & 0.14 & 0.11 \\
$\mathrm{~V}_{3}$ & 1.41 & 0.79 & 0.55 & 0.42 & 0.40 & 1.17 & 0.42 & 0.41 & 0.28 & 0.24 & 0.53 & 0.32 & 0.22 & 0.17 & 0.15 & 0.70 & 0.21 & 0.17 & 0.14 & 0.12 \\
$\mathrm{~V}_{4}$ & 2.51 & 0.75 & 0.49 & 0.38 & 0.40 & 1.25 & 0.62 & 0.46 & 0.29 & 0.22 & 0.61 & 0.37 & 0.26 & 0.18 & 0.18 & 0.74 & 0.30 & 0.18 & 0.14 & 0.12 \\
$\mathrm{~T}_{1}$ & 1.06 & 0.62 & 0.47 & 0.52 & 0.38 & 0.96 & 0.53 & 0.37 & 0.27 & 0.25 & 0.45 & 0.26 & 0.18 & 0.13 & 0.14 & 0.33 & 0.21 & 0.18 & 0.12 & 0.10 \\
$\mathrm{~T}_{2}$ & 1.53 & 0.83 & 0.57 & 0.46 & 0.43 & 1.19 & 0.51 & 0.39 & 0.28 & 0.24 & 0.55 & 0.33 & 0.19 & 0.17 & 0.17 & 0.70 & 0.22 & 0.15 & 0.12 & 0.12 \\
$\mathrm{~T}_{3}$ & 2.07 & 0.91 & 0.71 & 0.40 & 0.48 & 1.36 & 0.45 & 0.47 & 0.30 & 0.18 & 0.61 & 0.37 & 0.24 & 0.18 & 0.18 & 0.84 & 0.26 & 0.20 & 0.19 & 0.14 \\
$\mathrm{~T}_{4}$ & 1.60 & 0.80 & 0.50 & 0.42 & 0.40 & 1.12 & 0.47 & 0.38 & 0.27 & 0.24 & 0.51 & 0.30 & 0.19 & 0.15 & 0.14 & 0.59 & 0.22 & 0.14 & 0.11 & 0.10 \\
\hline
\end{tabular}
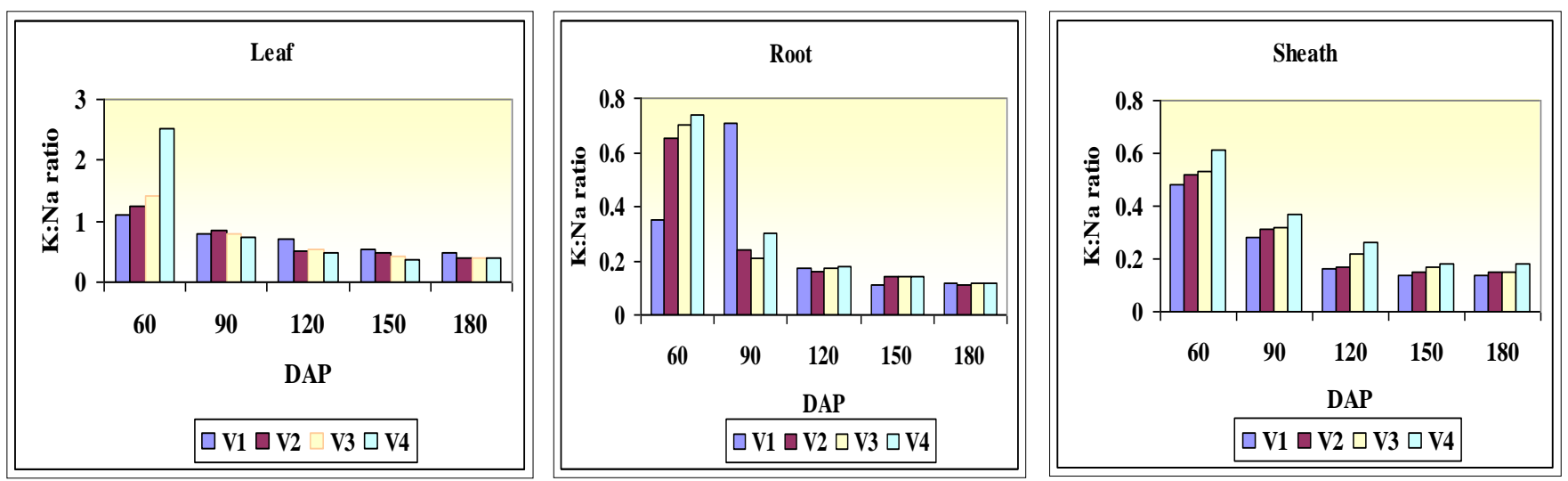

Fig 1 effect of amendments on $\mathrm{K}^{+}: \mathrm{N} . \mathrm{a}^{+}$ratio at different stages of sugarcane

This study strongly supports the hypothesis that $\mathrm{K}: \mathrm{Na}$ ratio play significant physiological role in sugarcane sodicity tolerance. Wider K: Na ratio in leaf at early stages (60 DAP) and in sheath at all stages could be used as an indicator of varietal tolerance to sodicity. Such roles of these metabolites are confined to the compartment where they accumulate; accumulation of higher $\mathrm{K}$ is of key importance to in the tolerance of sodicity. Further research is imperative for broad spectrum understanding the roles of those $\mathrm{K}$ : Na ratio in various plant species under sodicity conditions.

\section{LITERATURE CITED}

Abdul-Wahid A. 2006. Possible involvement of some secondary metabolites in salt tolerance of sugarcane. Journal of Plant Physiology 163: 723-730.

Franca S C, Roberto P G, Marins M A, Puga R D, Rodrigues A and Pereira J O. 2001. Biosynthesis of secondary metabolites in sugarcane. Genetic Molecular Biology 24: 243-250.

Francoise L E and Maas E V. 1999. Crop response and management on salt affected soils. In: (Eds) Pessarakli M. Handbook of plant and crop stress. New York: Marcel. pp 169-201.

Wahid A, Rao A R and Rasul E. 1997. Identification of salt tolerance traits in sugarcane lines. Field Crops Research 54: 917. 